\title{
Effect of $\alpha$-receptor blockers on lower urinary tract symptoms, sexual function and quality of life in young and middle-aged men with benign prostatic hyperplasia
}

\author{
TONGQING WANG $^{1 *}$, LEI WANG $^{1 *}$, YALIN LIANG $^{2}$, JIECHANG JU $^{3}$, YI CAI $^{1}$, JIE ZHANG $^{1}$, \\ HONGTAO ZHEN $^{1}$, YAOLEI LIU ${ }^{1}$, XIAOLONG TANG ${ }^{1}$, JIZHENG WANG ${ }^{1}$ and JIAN LIU ${ }^{1}$
}

\begin{abstract}
${ }^{1}$ Department of Urology Ward One, Zhengzhou Central Hospital Affiliated to the Zhengzhou University, Zhengzhou, Henan 450007; ${ }^{2}$ Department of Nephrology, Zhengzhou Seventh People's Hospital, Zhengzhou, Henan 450000; ${ }^{3}$ Department of Andrology, Zhengzhou Central Hospital Affiliated to the Zhengzhou University, Zhengzhou, Henan 450007, P.R. China
\end{abstract}

Received February 16, 2017; Accepted May 17, 2017

DOI: 10.3892/etm.2017.4518

\begin{abstract}
The purpose of the present study was to compare the effectiveness of two common $\alpha_{1}$-receptor blockers, alfuzosin and tamsulosin, on lower urinary tract symptoms, sexual function, and quality of life in young and middle-aged people with benign prostatic hyperplasia. We recruited 80 young and middle-aged patients with benign prostatic hyperplasia and divided them into two groups that received either the non-selective $\alpha_{1}$-receptor blocker alfuzosin or the selective $\alpha_{1 \mathrm{~A}}$-receptor blocker tamsulosin for 18 consecutive days. After intervention, maximum urinary flow, bladder compliance, maximum detrusor pressure, maximum urethral pressure, $72 \mathrm{~h}$ urination frequency and urination frequency at night, average urinary volume, residual urinary volume, urinary symptom distress score were significantly better in the tamsulosin group than in the alfuzosin group. Also, sperm density, sperm motility, sperm activity, and sperm DNA fragmentation index were significantly better in the tamsulosin group compared to the alfuzosin group. Finally, international index of erectile function-5 scores, increased libido and erection, retrograde ejaculation, and the quality of life were significantly better in the tamsulosin group compared to the alfuzosin group. Overall, tamsulosin effectively relieved the lower urinary tract symptoms, improved semen quality, and increased sexual life
\end{abstract}

Correspondence to: Dr Jian Liu, Department of Urology Ward One, Zhengzhou Central Hospital Affiliated to the Zhengzhou University, 195 Tongbai Road, Zhengzhou, Henan 450007, P.R. China

E-mail: jpy62d@163.com

${ }^{*}$ Contributed equally

Key words: tamsulosin, alfuzosin, benign prostatic hyperplasia, lower urinary tract symptoms, sexual function, life quality and quality of life in young and middle-aged patients with benign prostatic hyperplasia.

\section{Introduction}

The development of medical technology has led to rapid improvements in endoscopic surgery. In particular, the use of endoscopy surgery has markedly reduced the proportion of open surgery for prostatic hyperplasia (1). Benign prostatic hyperplasia is mostly treated by minimally invasive procedures (2). Previous studies have confirmed that about $15 \%$ of the patients with normal sexual life before the onset of prostatic hyperplasia who received prostate surgery suffered erectile dysfunction (ED), especially young and middle-aged patients (3). Postoperative ED, retrograde ejaculation, and other surgical complications seriously affect sexual function.

To improve the quality of life of patients, it is critical to protect the sexual and urinary functions (4). $\alpha_{1}$-Adrenergic receptor blockers can effectively reduce the pressure on the bladder outlet and promote a smooth urinary flow. This relieves the clinical symptoms of benign prostatic hyperplasia and improves the lower urinary tract symptoms regardless of whether they receive surgery (5). At this time, a variety of selective $\alpha_{1}$-receptor blockers are available for clinical use (6). However, it is unclear which specific agents can improve lower urinary tract symptoms, male sexual function, and quality of life. Here, we investigated this question by comparing the benefits of alfuzosin and tamsulosin in a group of 80 young and middle-aged men suffering prostatic hyperplasia.

\section{Patients and methods}

Patient information. We recruited 80 young and middle-aged patients aged 30-60 years with benign prostatic hyperplasia admitted to Zhengzhou Central Hospital Affiliated to the Zhengzhou University from March 2013 to December 2015. Patients were diagnosed by clinical manifestations, urodynamic examination, and prostatic ultrasound. All patients signed the informed consent forms before enrollment. The study was approved by the Ethics Committee of the 
Zhengzhou Central Hospital Affiliated to the Zhengzhou University. Urinary function before onset was normal; after the onset, patients urinated immediately after the micturition desire, and it was difficult to control. Patients urinated more than 8 times per day and 3 times at night. Exclusion criteria: patients with serious cardiopulmonary and renal dysfunction, urinary dysfunction, urinary incontinence, clear urinary tract infection, coagulation dysfunction, severe cardiopulmonary, hepatic and renal dysfunction, mental illness, preoperative ED, reduced preoperative sperm quality, severe endocrine system diseases, and malignant tumors caused by other reasons. The 80 patients were equally divided into control and experimental groups according to the random number method.

Methods. Patients received symptomatic and supportive treatment, such as risk assessment, being alert to complications, and strengthening health education. The control group was treated with alfuzosin orally (NMPN H20010398; Shenyang Tianling Pharmaceutical Co., Ltd., Liaoning, China) (2.5 mg, 3 times per day), and the maximum daily dose was controlled within $10 \mathrm{mg}$. The experimental group received tamsulosin orally (NMPN J20140015; Astellas Pharma, Tokyo, Japan) ( $0.2 \mathrm{mg}, 1$ time per day). Patients in both groups were treated for 18 consecutive days.

Experimental indexes. We compared urodynamics after intervention, $72 \mathrm{~h}$ urination log record after intervention, urinary symptom distress scores before and after intervention, Semen production indexes after intervention, international index of erectile function-5 (IIEF-5) scores at different time points, indexes related to sexual function at 6 months after intervention, and quality of life scores before and after intervention.

\section{Evaluation criteria}

Urinary function. Postoperative urodynamics included the maximum flow, maximum detrusor systolic pressure, bladder compliance, and maximum urethral pressure of patients after surgery. Maximum urinary flow referred to the maximum amount of urine discharged from the urinary tract measured by chamber pot. The other indexes were measured with a bladder double-chamber piezometer tube combined with rectal piezometric tube as follows: normal saline was slowly and reversely injected into the bladder. The rectal tube was used to determine the changes in abdominal pressure, and the maximum pressure of detrusor under systolic pressure with the influences of abdominal pressure eliminated effectively, to understand bladder compliance, and determine the maximum urethral pressure.

Residual urinary volume. A Philips iU22 transabdominal B-ultrasound (Philips, Amsterdam, The Netherlands) was used for the measures. The residual urinary volume after the urination was recorded and each measurement was performed by the same ultrasound physician with more than 5 years of experience.

Urinary symptoms distress score. Assessment was by subjective perception to determine the degree of distress and tolerance to lower urinary tract symptoms. They were classified as happy, satisfied, generally satisfactory, generally unsatisfactory, and distressed or poor with 1-6 points (36 points in total). The higher the score, the more obvious the lower urinary tract discomfort symptoms were.

Urinary $\log$. Clinically known as the urinary frequency table, mainly used to record urination habits under living conditions. Generally recommended to record for $72 \mathrm{~h}$ continuously, including the total intake of liquid, urination time, urinary volume each time, number of episodes of urinary incontinence and environment, urinary volume during urinary incontinence, $72 \mathrm{~h}$ urination frequency, urination frequency at night, and average urinary volume.

Erectile function. Erectile function was evaluated using IIEF-5 scores (24 points in total). Scores below 21 points suggested ED.

Retrograde ejaculation. Retrograde ejaculation referred to the existence of ejaculation feeling during sexual intercourse, but without semen ejection from the urethra and urine analysis after sexual intercourse showed sperms in the urine. The enhanced sexual desire meant that the requirement of sex was increased by more than $50 \%$ on average every month.

Examination of semen. Routine semen examination was conducted before the discharge. Semen was collected with masturbation or instrument. DNA fragmentation index (DFI) was detected using sperm DNA fragment detection kit (SCD method) and observed under a light microscope at $x 40$. The sperm aureole in semen was compared to evaluate sperm damage and DNA fragmentation.

Quality of life. Quality of life was evaluated using the Nottingham Health Survey Questionnaire, including energy, pain, emotional changes, sleep quality, adaptability to social life, and physical activity. The full score for each item was 100 points, with the higher scores indicating the worse quality of life.

Statistical analysis. SPSS 19 (IBM Corp., Armonk, NY, USA) was used for statistical processing. Measurement data were presented as mean \pm standard deviation. t-test was used for the comparison of means between the two groups, chi-square test was used for the comparisons between the two groups, and analysis of variance (ANOVA) was used for comparing means within the group. $\mathrm{P}<0.05$ indicates that the difference was statistically significant.

\section{Results}

Demographic and functional distribution of patients. Distribution by gender, age, disease course, maximum urinary flow, bladder compliance, maximum detrusor pressure, maximum urethral pressure, $72 \mathrm{~h}$ urination frequency, urination frequency at night, average urinary volume, residual urinary volume, urinary symptom distress scores, sperm density, sperm motility, sperm activity, sperm DFI, IIEF-5 scores, and quality of life scores in the two groups are shown in Table I. We found no statistically significant differences in any of the parameters between the groups. 
Table I. General biometric and clinical data.

\begin{tabular}{|c|c|c|c|c|}
\hline Groups & Experimental & Control & t-test or $\chi^{2}$ & P-value \\
\hline Age (years) & $48.5 \pm 2.1$ & $48.6 \pm 2.1$ & 0.213 & 0.832 \\
\hline Course of disease (months) & $3.2 \pm 0.3$ & $3.3 \pm 0.3$ & 1.491 & 0.140 \\
\hline Maximum urinary flow (ml/sec) & $5.3 \pm 0.2$ & $5.3 \pm 0.3$ & 0.000 & 1.000 \\
\hline Maximum detrusor pressure $\left(\mathrm{cm} \mathrm{H}_{2} \mathrm{O}\right)$ & $8.1 \pm 0.3$ & $8.2 \pm 0.3$ & 1.491 & 0.793 \\
\hline Maximum urethral pressure $\left(\mathrm{cm} \mathrm{H}_{2} \mathrm{O}\right)$ & $20.4 \pm 1.5$ & $20.5 \pm 1.5$ & 0.298 & 0.766 \\
\hline Urination frequency during $72 \mathrm{~h}$ (times) & $56.6 \pm 2.9$ & $56.7 \pm 3.0$ & 0.152 & 0.880 \\
\hline Urination frequency at night (times) & $6.9 \pm 1.1$ & $7.0 \pm 1.1$ & 0.407 & 0.686 \\
\hline Average urinary volume (ml) & $89.5 \pm 2.9$ & $90.1 \pm 3.0$ & 0.909 & 0.366 \\
\hline Residual urinary volume (ml) & $115.8 \pm 11.3$ & $116.3 \pm 11.4$ & 0.197 & 0.844 \\
\hline Urinary symptom distress score (points) & $30.2 \pm 1.8$ & $30.3 \pm 1.8$ & 0.248 & 0.804 \\
\hline Sperm density $\left(10^{9} / 1\right)$ & $36.1 \pm 2.3$ & $36.2 \pm 2.4$ & 0.190 & 0.850 \\
\hline Sperm motility (\%) & $61.1 \pm 10.5$ & $60.9 \pm 10.6$ & 0.085 & 0.933 \\
\hline Sperm activity (\%) & $78.2 \pm 10.0$ & $77.3 \pm 10.1$ & 0.400 & 0.690 \\
\hline DFI $(\%)$ & $25.9 \pm 5.2$ & $26.0 \pm 5.1$ & 0.087 & 0.931 \\
\hline IIEF-5 score & $18.3 \pm 1.2$ & $18.2 \pm 1.2$ & 0.373 & 0.710 \\
\hline Quality of life score & $81.5 \pm 2.3$ & $81.6 \pm 2.3$ & 0.194 & 0.846 \\
\hline
\end{tabular}

DFI, DNA fragmentation index; IIEF-5, international index of erectile function-5.

Table II. Urodynamics after intervention (mean \pm standard deviation).

\begin{tabular}{|c|c|c|c|c|}
\hline Groups & $\begin{array}{l}\text { Maximum urinary } \\
\text { flow }(\mathrm{ml} / \mathrm{sec})\end{array}$ & $\begin{array}{l}\text { Bladder compliance } \\
\qquad\left(\mathrm{cm} \mathrm{H}_{2} \mathrm{O}\right)\end{array}$ & $\begin{array}{l}\text { Maximum detrusor } \\
\text { pressure }\left(\mathrm{cm} \mathrm{H}_{2} \mathrm{O}\right)\end{array}$ & $\begin{array}{l}\text { Maximum urethral } \\
\text { pressure }\left(\mathrm{cm} \mathrm{H}_{2} \mathrm{O}\right)\end{array}$ \\
\hline Experimental & $13.3 \pm 1.2$ & $35.0 \pm 3.1$ & $19.1 \pm 2.0$ & $42.1 \pm 3.1$ \\
\hline Control & $9.0 \pm 0.5$ & $26.5 \pm 1.3$ & $13.4 \pm 0.6$ & $37.5 \pm 2.3$ \\
\hline t-test & 20.920 & 15.992 & 17.265 & 7.537 \\
\hline P-value & $<0.001$ & $<0.001$ & $<0.001$ & $<0.001$ \\
\hline
\end{tabular}

Table III. Frequency of urination after intervention during $72 \mathrm{~h}$ (mean \pm standard deviation).

\begin{tabular}{lcccc}
\hline Groups & $\begin{array}{c}\text { Urination frequency } \\
\text { during } 72 \mathrm{~h} \text { (times) }\end{array}$ & $\begin{array}{c}\text { Urination frequency } \\
\text { at night (times) }\end{array}$ & $\begin{array}{c}\text { Average urinary } \\
\text { volume (ml) }\end{array}$ & $\begin{array}{c}\text { Residual urinary } \\
\text { volume }(\mathrm{ml})\end{array}$ \\
\hline Experimental & $23.5 \pm 1.9$ & $2.5 \pm 0.3$ & $256.3 \pm 25.1$ & $8.1 \pm 1.3$ \\
Control & $43.2 \pm 5.1$ & $5.1 \pm 1.1$ & $118.9 \pm 16.3$ & $66.5 \pm 4.9$ \\
t-test & 22.893 & 15.364 & 29.036 & 72.858 \\
P-value & $<0.001$ & $<0.001$ & $<0.001$ & $<0.001$ \\
\hline
\end{tabular}

Urodynamics after treatment. After intervention, the maximum urinary flow, the bladder compliance, the maximum detrusor pressure, and the maximum urethral pressure in the experimental group was higher than in the control group (Table II).

Urination log record after treatment. After intervention, the $72 \mathrm{~h}$ urination frequency, the urination frequency at night, the average urinary volume, and the residual urinary were lower in the experimental group than those in the control group (Table III).
Urinary symptom distress scores before and after treatment. The difference in urinary symptom distress between the two groups before the intervention was not statistically significant (Table IV). However, the urinary symptom distress after intervention was significantly higher in the experimental group than that in the control group (Table IV).

Semen indexes after intervention. Sperm density, sperm motility, and sperm activity after intervention were higher in the experimental group than those in the control group (Table V). 
Table IV. Urinary distress scores before and after intervention (mean \pm standard deviation).

\begin{tabular}{|c|c|c|c|c|}
\hline Groups & Before intervention & After intervention & t-test & P-value \\
\hline Experimental & $30.2 \pm 1.8$ & $5.9 \pm 0.3$ & 84.220 & $<0.001$ \\
\hline Control & $30.3 \pm 1.8$ & $20.4 \pm 1.2$ & 28.943 & $<0.001$ \\
\hline t-test & 0.248 & 74.140 & - & - \\
\hline P-value & 0.804 & $<0.001$ & - & - \\
\hline
\end{tabular}

Table V. Indexes related to semen after intervention (mean \pm standard deviation).

\begin{tabular}{|c|c|c|c|c|}
\hline Groups & Sperm density $\left(10^{9} / 1\right)$ & Motility (\%) & Activity (\%) & DFI $(\%)$ \\
\hline Experimental & $45.1 \pm 2.3$ & $81.1 \pm 11.5$ & $78.2 \pm 10.0$ & $8.9 \pm 1.3$ \\
\hline Control & $24.2 \pm 1.4$ & $58.9 \pm 9.1$ & $55.6 \pm 8.1$ & $31.0 \pm 5.1$ \\
\hline t-test & 49.092 & 9.574 & 11.107 & 26.557 \\
\hline P-value & $<0.001$ & $<0.001$ & $<0.001$ & $<0.001$ \\
\hline
\end{tabular}

DFI, DNA fragmentation index.

Table VI. IIEF-5 scores at different time points (mean \pm standard deviation).

\begin{tabular}{|c|c|c|c|c|c|}
\hline Groups & Before intervention & 3 months after intervention & 6 months after intervention & $\mathrm{F}$ & P-value \\
\hline Experimental & $18.3 \pm 1.2$ & $21.3 \pm 0.4$ & $22.3 \pm 0.5$ & 18.569 & $<0.001$ \\
\hline Control & $18.2 \pm 1.2$ & $19.4 \pm 1.2$ & $20.6 \pm 0.4$ & 23.361 & $<0.001$ \\
\hline t-test & 0.373 & 9.500 & 16.791 & - & - \\
\hline P-value & 0.710 & 0.000 & $<0.001$ & - & - \\
\hline
\end{tabular}

IIEF-5, international index of erectile function-5.

Table VII. Sexual function indexes 6 months after intervention (cases).

\begin{tabular}{lccc}
\hline Groups & Increased libido & Enhanced erection function & Retrograde ejaculation \\
\hline Experimental & 19 & 21 & 2 \\
Control & 6 & 9 & 11 \\
$\chi^{2}$ & 8.378 & 6.453 & 5.878 \\
P-value & 0.004 & 0.011 & 0.015 \\
\hline
\end{tabular}

Table VIII. Quality of life scores before and after intervention (points, mean \pm standard deviation).

\begin{tabular}{|c|c|c|c|c|}
\hline Groups & Before intervention & After intervention & t-test & P-value \\
\hline Experimental & $81.5 \pm 2.3$ & $35.3 \pm 1.1$ & 114.608 & $<0.001$ \\
\hline Control & $81.6 \pm 2.3$ & $56.6 \pm 1.7$ & 55.823 & $<0.001$ \\
\hline t-test & 0.194 & 66.530 & - & - \\
\hline P-value & 0.846 & $<0.001$ & - & - \\
\hline
\end{tabular}

DFI was lower in the experimental group than that in control group (Table V).
IIEF-5 scores at different time points. The difference in IIEF-5 scores between the two groups before intervention was 
not statistically significant (Table VI). After 3 and 6 months of intervention, IIEF-5 scores were higher in experimental group than those in the control group (Table VI).

Sexual function 6 months after intervention. The increase in libido and erection function were higher in the experimental group than those in the control group (Table VII). In contrast, the rate of retrograde ejaculation was lower in the experimental group than that in the control group (Table VII).

Quality of life scores before and after intervention. The difference in quality of life scores before intervention between the two groups was not statistically significant (Table VIII). The quality of life scores for both groups were superior after intervention compared to those before intervention (Table VIII), but the scores for experimental group were higher than that for the control group (Table VIII).

\section{Discussion}

With the change of living and eating habits, the onset of benign prostatic hyperplasia has showed a younger trend (7). Benign prostatic hyperplasia has become the most common urinary disease in young and middle-aged men. This disease leads to urinary tract obstruction and lower urinary tract symptoms, such as frequent urination, urgent urination and dysuria. Longer disease course or acute obstructions also cause acute renal insufficiency, and patients complicated with severe cardiovascular disease may even suffer from acute myocardial infarction because of urination difficulty (8). Therefore, benign prostatic hyperplasia seriously reduces the quality of life and endangers the lives of patients (9). The preferred treatment is surgery, but the operation is not widely recommended due to the trauma and postoperative complications (10). Some patients, especially young and middle-aged patients with relatively mild symptoms, receive a conservative drug treatment (11). However, a dozen of selective $\alpha_{1}$-receptor blockers are used in the treatment of benign prostatic hyperplasia (12). The present study compared the effectiveness of two commonly-used selective $\alpha_{1}$-receptor blockers, alfuzosin and tamsulosin.

Examining multiple parameters of urinary function, we found that the ultra-selective $\alpha_{1}$-receptor blocker tamsulosin improved the performance of alfuzosin in all parameters. Thus, tamsulosin treatment can effectively improve bladder compliance in young and middle-aged patients with benign prostatic hyperplasia. This may be possibly accomplished because tamsulosin can selectively act on the smooth muscles of the urinary tract system, relieve spasms (13), and reduce the aseptic inflammatory response in the prostate tissues, thus improving the urinary function of patients (14). Tamsulosin can also act on the sympathetic nervous system of the pelvic floor, promote the relaxation of the pelvic floor muscles, and alleviate pain and discomfort caused by muscle tension in the perineum, the urethra, and the pelvic floor $(15,16)$.

In addition, the comparisons of indexes for semen production and quality, sexual function and satisfaction, and overall quality of life showed that tamsulosin performed better than alfuzosin in all parameters. The semen quality after tamsulosin was better than that in patients treated with alfuzosin because the latter acted on all the $\alpha_{1}$-adrenergic receptors in the sympathetic nervous system of the sperm transport pathway. This leads to the contraction of smooth muscles in the reproductive system and inhibits the contraction of smooth muscles in seminal vesicle and ejaculatory duct (17), thus blocking sperm transport. Tamsulosin is an ultra-selective $\alpha_{1}$-adrenergic receptor blocker, which reduces the impact on the smooth muscles of the male reproductive system without affecting the transport and release of semen (18), and reduces the incidence of ejaculation pain. The improvement of quality of life after tamsulosin is due to the selective block of the spinal semen secretion center and ejaculatory center $\alpha_{1 \mathrm{D}}$-receptor, thereby reducing sexual excitability and increasing the ejaculation threshold (19). This activity also significantly relaxed the smooth muscles of the above structures via blocking $\alpha_{1 \mathrm{~A}}$-receptors in the seminiferous duct, seminal vesicle, ejaculatory duct, and prostate to delay the ejaculation (20). The enhanced erectile function might be due to tamsulosin block of $\alpha_{1 \mathrm{~A}}$-receptor, better regulating the contraction and relaxation of penile corpus cavernosum, and increasing blood flow into the corpus cavernosum under sexual excitement, thereby increasing the penis hardness and improving libido. Tamsulosin, also inhibited the $\alpha_{1}$-receptors in the bladder neck, posterior urethra, and prostate, thus eliminating the smooth muscle spasms in the urethra, reducing the pressure within the urethra, and slowing the reflux of prostatic fluid during ejaculation, reducing retrograde ejaculation.

In conclusion, tamsulosin is more effective than alfuzosin in relieving the lower urinary tract symptoms, it improves the semen quality, sexual life, and quality of life in young and middle-aged patients with benign prostatic hyperplasia.

\section{Acknowledgements}

The present study was supported by the Guiding plan for medical science research of Henan Province 2015 (funding no. 201504076)

\section{References}

1. Michel MC: Words of wisdom: Re: a randomized controlled study of the efficacy of tamsulosin monotherapy and its combination with mirabegron for overactive bladder induced by benign prostatic obstruction. Eur Urol 69: 174-179, 2016.

2. Li H, Yang J, Zhao H, Fossler MJ and Wang C: Effect of tamsulosin on the pharmacokinetics of dutasteride in Chinese male healthy volunteers. Clin Pharmacol Drug Dev 4: 427-433, 2015.

3. Dimitropoulos K and Gravas S: Fixed-dose combination therapy with dutasteride and tamsulosin in the management of benign prostatic hyperplasia. Ther Adv Urol 8: 19-28, 2016.

4. Kaplan SA: Re: comparison of tamsulosin plus serenoa repens with tamsulosin in the treatment of benign prostatic hyperplasia in Korean men: 1-year randomized open label study. J Urol 196: 503-505, 2016.

5. Nazir J, Heemstra L, van Engen A, Hakimi Z and Ivanescu C: Cost-effectiveness of a fixed-dose combination of solifenacin and oral controlled adsorption system formulation of tamsulosin in men with lower urinary tract symptoms associated with benign prostatic hyperplasia. BMC Urol 15: 41-45, 2015.

6. Traish AM, Haider KS, Doros G and Haider A: Finasteride, not tamsulosin, increases severity of erectile dysfunction and decreases testosterone levels in men with benign prostatic hyperplasia. Horm Mol Biol Clin Investig 23: 85-96, 2015.

7. Udeh EI, Ofoha CG, Adewole DA and Nnabugwu II: A cost effective analysis of fixed-dose combination of dutasteride and tamsulosin compared with dutasteride monotherapy for benign prostatic hyperplasia in Nigeria: a middle income perspective; using an interactive Markov model. BMC Cancer 16: 405, 2016. 
8. Stojanović N, Ignjatović I, Djenić N and Bogdanović D: Adverse effects of pharmacological therapy of benign prostatic hyperplasia on sexual function in men. Srp Arh Celok Lek 143: 284-289, 2015

9. Kosilov KV, Loparev SA, Ivanovskaya MA and Kosilova LV: Effectiveness of solifenacin and trospium for managing of severe symptoms of overactive bladder in patients with benign prostatic hyperplasia. Am J Men Health 10: 157-163, 2016.

10. Russo A, Capogrosso P, La Croce G, Ventimiglia E, Boeri L, Briganti A, Damiano R, Montorsi F and Salonia A: Serenoa repens, selenium and lycopene to manage lower urinary tract symptoms suggestive for benign prostatic hyperplasia. Expert Opin Drug Saf 15: 1661-1670, 2016.

11. Krivoborodov GG and Tur EI: Long-term outcomes of the use of $\alpha$-blockers tamsulosin in men with lower urinary tract symptoms and benign prostatic hyperplasia. Urologiia 12: 47-48, 50, 2014 (In Russian).

12. Karami H, Hassanzadeh-Hadad A and Fallah-Karkan M: Comparing monotherapy with tadalafil or tamsulosin and their combination therapy in men with benign prostatic hyperplasia: a randomized clinical trial. Urol J 13: 2920-2926, 2016.

13. Barkin J, Diles D, Franks B and Berner T: Alpha blocker monotherapy versus combination therapy with antimuscarinics in men with persistent LUTS refractory to alpha-adrenergic treatment: patterns of persistence. Can J Urol 22: 7914-7923, 2015.

14. Fusco F, Palmieri A, Ficarra V, Giannarini G, Novara G, Longo N, Verze P, Creta M and Mirone V: $\alpha 1$-blockers improve benign prostatic obstruction in men with lower urinary tract symptoms: a systematic review and meta-analysis of urodynamic studies. Eur Urol 69: 1091-1101, 2016.
15. Utsunomiya N, Matsumoto K, Tsunemori H, Muguruma K, Kawakita M, Kamiyama Y, Kanamaru S, Ito N, Tsukazaki H, Shirahase T, et al: A crossover comparison study on lower urinary tract symptoms with overactive bladder secondary to benign prostatic hyperplasia: naftopidil versus tamsulosin with solifenacin. Hinyokika Kiyo 62: 341-347, 2016 (In Japanese).

16. Latil A, Pétrissans MT, Rouquet J, Robert G and de la Taille A: Effects of hexanic extract of serenoa repens (Permixon ${ }^{\circledR}$ $160 \mathrm{mg}$ ) on inflammation biomarkers in the treatment of lower urinary tract symptoms related to benign prostatic hyperplasia. Prostate 75: 1857-1867, 2015

17. Choi JD, Kim JH and Ahn SH: Transitional zone index as a predictor of the efficacy of $\alpha$-blocker and $5 \alpha$-reductase inhibitor combination therapy in Korean patients with benign prostatic hyperplasia. Urol Int 96: 406-412, 2016.

18. Takeshita H, Moriyama S, Arai Y, Washino S, Saito K, Chiba K, Horiuchi S and Noro A: Randomized crossover comparison of the short-term efficacy and safety of single half-dose silodosin and tamsulosin hydrochoride in men with lower urinary tract symptoms secondary to benign prostatic hyperplasia. Low Urin Tract Symptoms 8: 38-43, 2016.

19. Terakado M, Suzuki H, Hashimura K, Tanaka M, Ueda H, Kohno H, Fujimoto T, Saga H, Nakade S, Habashita H, et al: Discovery of ONO-7300243 from a novel class of lysophosphatidic acid receptor 1 antagonists: from hit to lead. ACS Med Chem Lett 7: 913-918, 2016.

20. Seftel AD: Re: finasteride, not tamsulosin, increases severity of erectile dysfunction and decreases testosterone levels in men with benign prostatic hyperplasia. J Urol 195: 139, 2016. 